\title{
Inclusão Digital no campo: implantação e expansão da Internet no meio rural da região extremo oeste catarinense
}

\author{
Jocinei Marcos da Silva \\ Centro Universitário FAI \\ Itapiranga, SC - Brasil \\ jocineisilva2669@gmail.com
}

\author{
Juliane Colling \\ Universidade de Lisboa \\ Lisboa, Portugal \\ juliane@uceff.edu.br
}

\author{
Sibele Mueller \\ Centro Universitário FAI \\ Itapiranga, SC - Brasil \\ sibele@uceff.edu.br
}

\begin{abstract}
Internet has become something very essential in the daily life of the population, for the execution of tasks from the simplest to the most difficult, both in the city and in the countryside. Researches and daily accesses are carried out to consult climate data or even access to information from producers integrated into poultry and swine companies. In this sense, this research aims to identify how the process of expanding Internet access occurred in rural areas in the municipalities of the extreme west of Santa Catarina, which locations do not yet have access to the Internet and what are the impacts of digital inclusion for the rural population. To reach the objective, the research used an exploratory methodology, performing data collection through a questionnaire applied to residents and companies providing telecommunications services within the municipalities of Itapiranga, São João do Oeste, Iporã do Oeste, Tunápolis , Santa Helena and Mondaí. These municipalities were chosen because they are in an area of great production, involving poultry, swine, dairy, beef cattle, in addition to agriculture. The questionnaire developed was applied through WhatsApp, and 30 responses were obtained from the questionnaire applied to them, with two Internet service providers. They are: Nedel Telecom and UltraWeb Telecomunicações LTDA, which also answered a questionnaire about the current demands and problems faced by them, in addition - of course, of the possible improvements that they can implement, or that are under study for future applications. As a result, it was identified that since the beginning of the implementation of the Internet system, there has been a good evolution in the signal made available to customers, and in the same way, companies continue their expansion and improvements, with equipment changes both in the homes of customers, as well as in transmission towers and mirrors, all to provide a better quality signal and greater signal stability, as well as greater comfort for users of the system. These accesses are made in several ways, from cell phones to desktop computers and notebooks. Another important fact noticed is the evolution in the delivery of the Internet signal offered in the interior, which in recent years has improved a lot, leaving the 2.4 Ghz technology, and evolving to the $5 \mathrm{Ghz}$ technology. It is concluded that the Internet has brought important improvements for the rural population, but there are still improvements to be made to promote greater rural digital inclusion.
\end{abstract}

Resumo - A Internet se tornou algo muito essencial no dia a dia da população, para a execução de tarefas das mais simples até as mais difíceis, tanto na cidade quanto no campo. São realizadas pesquisas e acessos diários para consulta de dados sobre clima ou mesmo acessos às informações dos produtores integrados às empresas de aves e suínos. Neste sentido, esta pesquisa tem como objetivo identificar como ocorreu o processo de expansão de acesso à Internet no meio rural nos municípios da região extremo oeste de Santa Catarina, quais localidades ainda não possuem acesso à Internet e quais os impactos da inclusão digital para a população rural. Para alcançar o objetivo, a pesquisa utilizou-se de metodologia exploratória, realizando coleta de dados por meio de questionário aplicado à moradores e as empresas prestadoras do serviço de telecomunicações no interior dos municípios de Itapiranga, São João do Oeste, Iporã do Oeste, Tunápolis, Santa Helena e Mondaí. Estes municípios foram escolhidos por ficarem em uma área de grande produção, envolvendo avicultura, suinocultura, setor leiteiro, gado de corte, além da agricultura.

O questionário desenvolvido, foi aplicado através do WhatsApp, onde foi obtido 30 respostas do questionário aplicado a eles, e é composta por duas empresas provedoras de Internet. São ela: Nedel Telecom e UltraWeb Telecomunicações LTDA, sendo que estas também responderam questionário sobre as atuais demandas e problemas enfrentados por elas, além é claro, das possíveis melhorias que estejam implementando, ou que estejam em estudo para aplicações futuras.

Como resultados identificou-se que desde o início da implementação do sistema de Internet, houve uma boa evolução no sinal entregue aos clientes, sendo que da mesma forma, continua sua expansão e suas melhorias, com trocas de equipamentos tanto nas casas dos clientes, quanto nas torres e espelhos de transmissão, tudo para entregar um sinal de melhor qualidade e maior estabilidade no sinal, bem como um maior conforto aos usuários do sistema. Esses acessos são feitos por diversas formas, desde celulares a computadores de mesa e notebooks. Outro fato importante percebido é a evolução na entrega do sinal de Internet oferecido no interior, que nos últimos anos melhorou muito, saindo da tecnologia $2.4 \mathrm{Ghz}$, e evoluindo para a tecnologia $5 \mathrm{Ghz}$. Conclui-se então que a Internet trouxe melhorias importantes para a população rural, mas ainda há melhorias a serem realizadas para promover maior inclusão digital rural.

Palavras-chave - Inclusão Digital; Rural; Comunicação Rural; Melhoria de sinal. 


\section{INTRODUÇÃO}

No contexto atual, é indispensável o uso da tecnologia nas mais diversas áreas e atividades do nosso dia a dia, que vão desde as empresas de pequeno porte, propriedades rurais, até as multinacionais, tornando assim, a intercomunicação de dados fácil, ágil e quase simultânea. No contexto atual, a maior oferta de Internet disponível no mercado se concentra nas mãos de grandes empresas, que oferecem uma boa conectividade em grandes centros urbanos, mas pecam no fornecimento de sinal de telefonia e Internet no meio rural.

Desta forma, os pequenos provedores de Internet vem crescendo de forma significativa há um bom tempo, levando sinal aos locais mais remotos das pequenas comunidades e, desta maneira, contribuem para a inclusão digital aos mais distantes e às comunidades mais afastadas dos centros urbanos. Segundo um estudo divulgado pela Anatel em 2018, 69 milhões de domicílios brasileiros ainda não contam com Internet de banda larga em suas residências, totalizando um percentual de $57 \%$ dos lares. O mesmo estudo divulgou que de 2014 até março de 2018 houve um crescimento de $23 \%$ de acessos fixos, subindo de 24,2 para 29,7 milhões (TOOGE, 2020)

Em 2017, o IBGE divulgou dados do censo agrícola, onde traz à tona a realidade do número de propriedades rurais que ainda permanecem sem um sistema de conexão. Ainda segundo esses dados, na época, o índice de residências sem Internet ultrapassava a faixa dos 3,6 milhões de moradias desconectadas, que chegavam a impressionantes $71,8 \%$ das residências sem Internet (TOOGE, 2020).

Esses índices porém, não condizem com os dados observados na região no extremo-oeste de Santa Catarina que conta com um efetivo de cerca de $95 \%$ das residências atendidas com conexão de Internet. Ainda existe um mercado a ser suprido nesta região, porém o número residências que ainda necessitam ser conectadas com a rede mundial de computadores é baixa (NEDEL, 2019).

Após dois anos desde a pesquisa do IBGE, houve uma nova pesquisa realizada em 2019 , desta vez realizada pelo Centro Regional de Estudos para o Desenvolvimento da Sociedade da Informação (CETIC, 2019), que desenvolve pesquisas anuais nos domicílios brasileiros e esta demonstrou que cerca de $70 \%$ das residências estão conectadas à Internet através da banda larga ou por meio da tecnologia wireless. Segundo a Cetic, atualmente no Brasil, cerca de $50 \%$ das residências rurais estão conectadas.

As grandes mudanças observadas no meio rural nos últimos 30 anos geraram uma necessidade de adaptações por parte dos produtores a essa nova realidade, em que a produção de subsistência deu lugar a um complexo sistema agroindustrial, fazendo desta forma que as fronteiras entre rural e urbano tornem-se menores. O conhecimento deixou de ser privilégio e tornou-se fator de desenvolvimento da agricultura, sendo necessário para isso que os produtores tenham acesso à informação e aos meios de telecomunicação (BERNARDES et al, 2015).

Outro fator importante segundo Massruhá e Leite (2014), é que a Agro 4.0 traz para o setor agrário e agrícola métodos computacionais de alto desempenho como: circuitos de sensores; uma nova forma de comunicação, o
M2M, que se refere a comunicação maquina para maquina; a diversidade de comunicação entre dispositivos móveis; o armazenamento de dados em nuvem; sistema de BI e sistemas de suporte à tomada de decisões de manejo. Desta forma contribui para $\mathrm{o}$ aumento da produtividade, diminuindo a quantidade de insumos aplicados, reduzindo a mão de obra e seus custos, diminuindo os custos ao meio ambiente e reduzindo riscos exponenciais a saúde dos trabalhadores. Neste contexto pode-se citar também a agricultura de precisão, Big Data, IOT, automação e robótica.

Desta forma, essa pesquisa visa desenvolver um estudo que apresente uma trajetória de crescimento e expansão do fornecimento de Internet no meio rural na região extremo oeste catarinense, mais especificamente nos municípios de Itapiranga, São João do Oeste, Tunápolis, Santa Helena, Iporã do Oeste e Mondaí, buscando junto às empresas que dão suporte e fornecimento da Internet à estas cidades, dados históricos e atuais, a fim de identificar o percurso histórico de expansão da Internet rural e a cobertura atual do serviços no meio rural, bem como a visão dos agricultores sobre os impactos após a implantação da Internet em suas residências.

A escolha dos seis municípios da região do extremo-oeste de Santa Catarina, deu-se em virtude dos autores residirem atualmente nesta região e por estes municípios terem maior parte da sua população residente em áreas rurais e este ser o setor que mais movimenta estes municípios, sendo desta forma de grande valia que estes locais possam ter acesso à Internet de qualidade, de maneira a auxiliar suas atividades rurais e a automatização de processos.

A relevância deste estudo caracteriza-se pela construção de um panorama histórico e atual sobre a inclusão digital no campo nos municípios desta região, de forma que possamos compreender o processo de expansão de acesso à Internet $\mathrm{e}$ dar subsídios informativos para que empresas e órgãos públicos desenvolvam ações a fim de atender a população que hoje ainda não possui acesso à Internet em suas residências. Além disso, a entrevista com pessoas do meio rural visa destacar os impactos e mudanças que a inclusão digital no campo trouxe para a região.

\section{METODOLOGIA}

Esta pesquisa caracteriza-se como uma pesquisa qualitativa, tendo em vista o resgate histórico de informações e análise do panorama atual de acesso à Internet no meio rural, utilizando-se de dados de empresas e relatos de pessoas acerca do processo de expansão da Inclusão Digital e as mudanças proporcionadas à população rural a partir da possibilidade de conexão à Internet.

Adotou-se um caminho metodológico de caráter exploratório, onde o investigador entrou em contato direto com grupos e indivíduos para a aquisição das informações, bem como com a situação e o ambiente investigado, para um melhor aprofundamento dos dados obtidos.

De acordo com Rodrigues (2007), pesquisa exploratória busca se familiarizar com os fenômenos surgidos durante a pesquisa, explorando os próximos passos mais profundamente e com maior precisão, desta forma elevando a veracidade dos dados obtidos. 
A coleta dos dados foi feita entre os meses de fevereiro a outubro de 2020, por meio da utilização do método de entrevista que foi realizada com empresários e profissionais da área de telecomunicações da região do extremo oeste de Santa Catarina e com a população rural atendida com Internet, porém, em decorrência da situação de isolamento social demandada pela pandemia de COVID-19, a coleta de dados realizada com moradores da zona rural, que iniciou-se de forma presencial junto às propriedades, passou a ser realizada de forma online, por meio de envio de questionário em grupos de WhatsApp de agricultores. Participaram da pesquisa 30 famílias residentes no meio rural dos municípios citados e também os proprietários das duas empresas de telecomunicações responsáveis pela cobertura de Internet nesta região.

\section{RESULTADOS E DISCUSSÃO}

Houve, há alguns anos a introdução da Internet no meio rural com a tecnologia wireless. Por volta de 2006, começou a introdução desse sistema na região do extremo oeste de Santa Catarina pelo provedor Nedel Telecom. Eram oferecidos planos de baixa capacidade, por volta de 256 kbps, sendo estes planos suficientes, na época, para suprir a demanda dos produtores rurais.

O tempo foi passando e a demanda por velocidade aumentou, gerando, desta forma, a necessidade de implementações e mudanças na rede já instalada. Novos pontos tiveram de ser instalados, assim como novas tecnologias, que o caso da Internet de 5GHZ. Mudanças tiveram de ser realizadas, como a substituição de vários pontos, que antes eram postes de madeira ou concreto por torres que fornecem uma altura muito maior para atender a mais clientes e a substituição das células de fornecimento de Internet. Atualmente existem células de telefonia 4G, chamadas de LTEs, para testes de fornecimento de Internet, além de fornecimento de sinal telefônico.

Com relação ao acesso e melhorias realizadas no fornecimento de Internet no meio rural, foi questionado os produtores rurais sobre a receptividade da Internet em suas casas. Inicialmente questionou-se como era a vida deles antes da instalação do sistema de Internet em sua propriedade. Na totalidade das respostas, obtivemos $66,7 \%$ das respostas afirmando que havia muito menos agilidade nas comunicações, seguido por $53,3 \%$ afirmando que possuíam mais tempo disponível com a família e em torno de $43 \%$ confirmaram a falta de informações a nível mundial e a disponibilidade de maior tempo para ocupação com as tarefas diárias que correspondeu a $40 \%$ conforme apresentado no Quadro 1.

\begin{tabular}{|l|c|c|}
\hline Alternativa & Qtd & $\%$ \\
\hline $\begin{array}{l}\text { Maior tempo disponível com a } \\
\text { familia; }\end{array}$ & 16 & $53,30 \%$ \\
\hline Menos agilidade nas comunicações; & 20 & $66,70 \%$ \\
\hline Poucas informações a nível mundial; & 13 & $43,30 \%$ \\
\hline $\begin{array}{l}\text { Maior tempo para as ocupações } \\
\text { diárias com a casa e afazeres; }\end{array}$ & 12 & $40 \%$ \\
\hline
\end{tabular}

Quadro 1: Vida antes da Internet
Em seguida, foi questionado os agricultores sobre a forma de como a Internet contribuiu para a melhora de atividades realizadas no campo, onde $80 \%$ afirmam que melhorou muito a questão do contato com as empresas fornecedoras de implementos e produtos, seguido por $76,7 \%$ relatos de aumento dos acessos para obter informações em tempo real, como a previsão do tempo, seguido por $60 \%$ que afirmaram uma agilidade muito maior nas comunicações e $56,7 \%$ que afirmam o aumento na agilidade para o pagamentos de contas e realizações de compras, como pode ser observado no Quadro 2.

\begin{tabular}{l|c|c|}
\hline Alternativa & Qtd & $\%$ \\
\hline $\begin{array}{l}\text { Contato com empresas fornecedoras } \\
\text { de implementos e produtos; }\end{array}$ & 23 & $76,70 \%$ \\
\hline $\begin{array}{l}\text { Acesso a informações em tempo } \\
\text { real, como previsão do tempo, etc; }\end{array}$ & 24 & $80,00 \%$ \\
\hline $\begin{array}{l}\text { Agilidade nas comunicações; } \\
\begin{array}{l}\text { Pagamentos de contas e realizações } \\
\text { de compras; }\end{array}\end{array}$ & 18 & $60,00 \%$ \\
\hline
\end{tabular}

Quadro 2: contribuição no dia a dia

$\mathrm{Na}$ sequência foi perguntado como os agricultores, imaginam o futuro, considerando o uso diário da Internet em suas residências. Obtivemos $73,3 \%$ das respostas indicando que acreditam que será essencial, como já se observa nos dias atuais, 53,3\% afirmam que ela permitirá o acesso, ainda maior, à diversas informações diárias, $46,7 \%$ consideram que que seremos dependentes dela e 23,3\% mencionaram um aumento significativo na contribuição do uso da Internet na comunicação familiar. Os resultados obtidos podem ser observados no Quadro 3.

\begin{tabular}{l|c|c|}
\hline Alternativa & Qtd & $\%$ \\
\hline Será essencial; & 22 & $73,30 \%$ \\
\hline $\begin{array}{l}\text { Aumentará a comunicação com os } \\
\text { familiares; }\end{array}$ & 7 & $23,30 \%$ \\
\hline Maior número de informações; & 16 & $53,30 \%$ \\
\hline Dependente dela; & 14 & $46,70 \%$ \\
\hline
\end{tabular}

Quadro 3: perspectiva de futuro

Os agricultores também foram questionados sobre quais as funcionalidades mais utilizadas com o acesso à Internet $\mathrm{e}$ quais as pesquisas mais recorrentes realizadas por eles, sendo que o maior índice de busca são informações relacionadas à previsão do tempo, com $90 \%$, sendo este alto índice justificado pela necessidade desta informação no dia a dia do produtor rural, seja para planejamento pessoal, cultivo ou manejo das produções agrícolas. As pesquisas e contato com as empresas integradoras correspondem a $56,7 \%$, o uso de redes sociais equivale à $53,3 \%, 46,7 \%$ do uso está relacionado à utilização dela como auxílio para educação dos seus filhos e para participação das aulas remotas, devido ao atual cenário pandêmico que se vivencia e $33,3 \%$ a utilizam para manter contato com os familiares, como pode ser 
observado no Quadro 4.

\begin{tabular}{|l|c|c|}
\hline Alternativa & Qtd & $\%$ \\
\hline Redes sociais; & 16 & $53,30 \%$ \\
\hline $\begin{array}{l}\text { Noticias incluindo tempo, negócios; } \\
\text { esportes; }\end{array}$ & 27 & $90,00 \%$ \\
\hline Contato com os familiares; & 10 & $33,30 \%$ \\
\hline Educação; & 14 & $46,70 \%$ \\
\hline Contato com empresas integradoras; & 17 & $56,70 \%$ \\
\hline
\end{tabular}

Quadro 4: áreas de pesquisa

Outro questionamento realizado é em relação aos benefícios mais perceptíveis quanto a utilização da Internet. Como a resposta era livre, percebeu-se um grande volume de respostas relacionadas à agilidade das atividades na propriedades, em especial em relação às necessidades de busca de produtos na cidade. Ao invés de realizar o deslocamento é feito a solicitação via telefone (WhatsApp, email,etc.), e a empresa desloca seus funcionários para a entrega de produtos na casa do agricultor ou para a prestação de serviços, enquanto eles continuam com os afazeres da propriedade.

Outro questionamento foi em relação à percepção da evolução do sinal da Internet oferecido pelas empresas de telecomunicação nos locais onde os entrevistados residem. A maioria, $87,7 \%$, percebeu mudanças, enquanto um total de $13,4 \%$ não percebeu mudanças ou podem ter havido alterações, porém não foram perceptíveis aos participantes da pesquisa. $\mathrm{O}$ que é evidente na pesquisa é que a maioria percebeu a evolução do sinal e qualidade de internet, fruto de mudanças e melhorias nos equipamentos e tecnologias utilizadas pelos provedores de internet da região do extremo-oeste de Santa Catarina. Os dados podem ser observados no Quadro 5.

\begin{tabular}{|l|c|c|}
\hline Alternativa & Qtd & $\%$ \\
\hline Sim & 26 & $86,70 \%$ \\
\hline Não & 2 & $6,70 \%$ \\
\hline Talvez & 2 & $6,70 \%$ \\
\hline
\end{tabular}

Quadro 5: Evolução do sinal

Os participantes também foram questionados em relação ao valor que estão pagando pelo pacote de Internet entregue em sua casa. $\mathrm{O}$ intuito deste questionamento era saber se os valores praticados pelas empresas de telecomunicação eram considerados justo pelos participantes da pesquisa. Neste quesito $26,7 \%$ dos participantes afirmaram que o preço está bom, $23,3 \%$ que o preço não estava compatível e $10 \%$ disseram que talvez, conforme Quadro 6. Porém, a maioria, $40 \%$, responderam que estariam dispostos a pagar um valor maior se a qualidade da Internet também melhorasse. Neste ponto é perceptível que atualmente a qualidade de sinal de internet e sua disponibilidade é um fator importante para seus usuários, inclusive no meio rural, como podemos observar no Quadro 6.

\begin{tabular}{l|c|c|}
\hline Alternativa & Qtd & $\%$ \\
\hline Sim & 8 & $26,70 \%$ \\
\hline Não & 7 & $23,30 \%$ \\
\hline Talvez & 3 & $10,00 \%$ \\
\hline $\begin{array}{l}\text { Poderia ser melhor, mesmo que com } \\
\text { um valor maior; }\end{array}$ & 12 & $40,00 \%$ \\
\hline
\end{tabular}

Quadro 6: Valor cobrado pelo provedor

Em virtude dos dados obtidos durante a pesquisa, que evidenciaram uma cobertura quase total de sinal de Internet na região do extremo oeste de Santa Catarina e também da perceptível preocupação dos provedores em acompanhar a demanda e as tecnologias atuais em relação à equipamentos de fornecimento e cobertura de sinal de Internet, estendemos a pesquisa e coleta de dados para os provedores de Internet que atuam na região do extremo-oeste de Santa Catarina. Os dois provedores são: Nedel Telecom, localizada em Itapiranga, Santa Catarina e UltraWeb Telecomunicações LTDA, localizada na cidade de Mondaí, Santa Catarina. As respostas foram dadas por Henrique Nedel, proprietário da Nedel Telecom, e Marcos Roberto Contarin, diretor da UltraWeb.

É importante ressaltar que disponibilizamos as mesmas perguntas aos dois provedores, e na sequência serão disponibilizadas os nomes de cada empresa e suas respectivas respostas. A primeira pergunta é em relação a evolução da empresa em termos tecnológicos e cobertura de sinal nas cidades em que atuam, especialmente no meio rural. Para estas perguntas foram obtidas as seguintes respostas:

R. Nedel Telecom: São 14 anos de atuação na área rural de nossa região. Na tecnologia rádio, foi desenvolvida uma estrutura muito boa, garantindo cobertura de sinal para em torno de $95 \%$ do território e destaca-se a evolução tecnológica dos equipamentos utilizados onde inicialmente o maior plano vendido era de 128 KBits evoluiu para 10 Megabits. Na tecnologia fibra já são atendidos uma boa parcela dos clientes, principalmente as residentes próximas a rede Backbone.

R. UltraWeb: Devido à crescente demanda pelo uso da tecnologia da informação no meio rural, informatização das propriedades e acesso às plataformas de entretenimento online é obrigação de qualquer empresa melhorar a qualidade e velocidade das conexões no meio rural, assim faz a nossa empresa.

A segunda pergunta é voltada para a constante evolução em termos de expansão de rede e cobertura de sinal de Internet nas cidades onde atuam, sendo a pergunta voltada para as ações que a empresa está tomando nesse sentido.

R. Nedel Telecom: Na Internet via rádio o foco é utilizar tecnologia de ponta que garanta estabilidade $e$ disponibilidade, principalmente dimensionando a capacidade de cada POP de acordo com a demanda. Atualmente os novos pontos de atendimento são mais raros, visto que o 
meio já se encontra com boa cobertura. Na via fibra existem projetos de expansão para os locais que tem uma densidade demográfica maior.

R UltraWeb: Como toda empresa organizada e que quer crescer, nossa empresa trabalha constantemente na expansão e melhoria da área de cobertura.

Neste sentido, as empresas foram questionadas em relação aos projetos futuros ou em andamento para melhorar a qualidade de sinal ofertado às pessoas do meio rural.

R. Nedel Telecom: Fibra para onde é viável economicamente e no rádio o principal foco é a atualização tecnológica dos equipamentos explorando a sua maior capacidade de tráfego.

R. UltraWeb: Investir em equipamentos e tecnologias que permitam aumentar a velocidade de tráfego.

Os empresários foram questionados também sobre as principais e maiores dificuldades encontradas em relação à cobertura de sinal e aumento da qualidade e velocidades de Internet no meio rural, na qual foram obtidas as seguintes respostas:

R. Nedel Telecom: Na fibra a distância e a falta de disponibilidade de estrutura para o lançamento dos cabos. Já na via rádio o que mais dificulta são os obstáculos para a passagem do sinal, destacando os reflorestamentos que estão em expansão em nossa região.

R UltraWeb: O relevo da região que prejudica a transmissão de sinal via rádio e as distâncias e altos custos que prejudicam a inserção da fibra óptica no meio rural.

Atualmente a cobertura de internet no interior dos municípios onde foi realizada a pesquisa, em sua maioria, é de sinal via rádio, por este motivo procurou-se saber da existência de projetos, mesmo que futuros, de expansão da rede de fibra óptica para o meio rural, já que esta oferece um sinal mais estável, de melhorar qualidade e também facilmente escalável em termos de potência, sendo obtidas as seguintes respostas:

R. Nedel Telecom: Temos algumas redes em andamento e outras em estudo, mas o alto custo é um problema para viabilizar cobertura em $100 \%$ das áreas rurais.

R. UltraWeb: Devido aos fatores citados [nas outras perguntas] no momento não.

Como é possível observar, existem fatores que interferem na entrega e instalação, no meio rural, de tecnologias mais avançadas e com melhor qualidade em termos de velocidade e estabilidade, como é o caso da fibra óptica, sendo os principais empecilhos o alto custo e a dificuldade de chegar às regiões remotas do interior dos municípios. Da mesma forma, podemos salientar que o próprio relevo do extremo-oeste de Santa Catarina, formado por grandes montanhas, não contribui para um maior e melhor alcance de novas e das atuais tecnologias utilizadas como a via-rádio. Porém, é necessário, inclusive como forma de inclusão digital, que todos possam ter acesso à internet de qualidade, neste sentido, os empresários foram questionados sobre quais outras tecnologias, além das já citadas, poderiam ser uma alternativa para implementação do meio rural, sendo que as respostas foram as seguintes:

R. Nedel Telecom: Além da cobertura de Wi-Fi, existe a possibilidade de usar LTE já que a empresa é detentora de Faixa de frequência 2,5 Ghz para os municípios que hoje são atendidos. Atualmente ainda não é viável pelo custo da tecnologia e equipamentos mas no futuro pode ser uma boa opção.

R. UltraWeb: Hoje já disponibilizamos a melhor tecnologia acessivel e disponível que é sinal de rádio com frequência de $5.8 G h z$

Através dos dados coletados, tanto dos residentes nas áreas rurais quanto dos empresário que atendem, em termos de Internet, a região que foi foco desta pesquisa, é possível observar que, apesar das dificuldades encontradas para que se possa disponibilizar em todas áreas os melhores recursos de Internet disponíveis no mercado atualmente, o meio rural possui, em sua maioria, cobertura de Internet, o que os inclui digitalmente, favorece o crescimento através dos conhecimentos possíveis de serem encontrados neste meio em relação às atividades por eles realizados, permite várias facilidades, entre elas a comunicação e a possibilidade de usufruir da tecnologia para automatizar processos dos mais variados fins.

Com o aumento crescente na tecnologia 4.0 é de suma importância que as pessoas residentes no meio rural, em especial agricultores e produtores rurais possam usufruir das facilidades e vantagens que o acesso a esta ferramenta pode proporcionar, começando pela facilidade na realização de processos que antes eram realizados de forma manual, na automação das atividades importantes para os setores agropecuários, na interligação de equipamentos por meio de IOT, na cultura de precisão, assim como na análise de todas as informações geradas nos processos de agricultura que podem ser realizadas por meio do Business Analytics e se tornarem ferramentas poderosas para o processo de decisão.

Esta pesquisa, visa mostrar que é importante a inclusão digital no meio rural e que, este acesso, passa a ser não apenas forma de entretenimento e comunicação, mas abre uma infinidade de opções que podem ser utilizadas pelos produtores rurais para aumentar sua lucratividade no cultivo e manejo das produções. Por este motivo é de suma importância que se façam investimentos para que a Internet e a disponibilização da informação esteja em todos os ambientes, inclusive no meio rural.

\section{CONCLUSÃo}

Desta forma podemos concluir que nos últimos 10 a 14 anos tivemos uma evolução significativa na expansão dos sinais de Internet oferecidos ao produtor rural. As passagens de tecnologias fornecedoras de sinal evoluíram de forma significativa, entregando maior potência e qualidade de sinal, porém no meio rural onde a maior parte de cobertura ainda é realizada por meio da Internet via rádio, a mesma, por vezes, 
fica comprometida por quedas, especialmente em dias de chuva ou mesmo em dias de céu limpo. Com isso vê-se a necessidade de conseguir entregar uma Internet com maior estabilidade nessas comunidades.

Uma outra questão que interfere significativamente na qualidade da entrega e sinal da Internet e apresentada pelas prestadoras de Internet, é a questão da mata nativa que vem crescendo de forma significativa, bem como as plantações de eucalipto que são plantadas para proteção das propriedades de vendavais e intempéries. É necessário que se encontre uma forma de chegar ao meio rural com Internet de qualidade e que respeite os espaços de mata nativa e de reflorestamentos,

Neste sentido, percebe-se um empenho por parte dos provedores no investindo na manutenção de suas redes, com ampliação de sinal buscando satisfazer as necessidades daqueles que fazem uso diário da Internet, tanto para lazer, educação, agricultura, entretenimento, entre outros.

A Internet tornou-se uma ferramenta indispensável para os agricultores e as pessoas que residem nos meios rurais, que buscam sempre a excelência em seus trabalhos, a busca por maior produtividade, mantendo contato com as empresas integradoras, que através de meios de comunicação via Internet, se tornaram muito mais rápidas e práticas.

\section{Agradecimentos}

À agência financiadora desta pesquisa, o Programa de Bolsas Universitárias do Estado de Santa Catarina UNIEDU, por meio do Art. 170 da legislação estadual;

À família, na pessoa da esposa Sibele e filha Laís, que incentivaram para realização da pesquisa e compreenderam os momentos dedicados à ela.

À instituição de ensino, coordenadora do curso de Gestão da Tecnologia da Informação e orientadora desta pesquisa, Juliane Colling, e todas as demais pessoas envolvidas na realização da pesquisa.

\section{REFERÊNCIAS}

BERNARDES, J. C. et. al. O uso das tecnologias de informação e comunicação na agricultura familiar: um caminho para a sustentabilidade. Fórum ambiental da Alta Paulista, v.11, n.9, 2015. Disponível em: https://www.amigosdanatureza.org.br/publicacoes/index. php/forum_ambiental/article/view/1175/1198. Acesso em 15 nov. 2020.

CETIC. TIC Domicílios. Disponível em: https://cetic.br/pt/pesquisa/domicilios/. Acesso em 15 nov. 2020.

FELICIANO, A. M.; LAPOLLI, E. M; WILERDING, I. A.; SOUZA, V. A. B. Inclusão Digital Rural: Capilaridade para ações de Governo Eletrônico. Revista Democracia Digital e Governo Eletrônico. v.2, n.3, 2010. Disponível em: http://buscalegis.ufsc.br/revistas/index.php/observatorio doegov/article/view/31. Acesso em 04 nov. 2020.
LIMA, G. K. A. Atividade de aprendizagem: Tipo de pesquisas científicas. Web Artigos. 2014. Disponível em:

$<$ https://www.webartigos.com/artigos/atividade-de-apre ndizagem-tipo-de--pesquisas-cientifica/124262> Acessado em 26 de ago. 2019.

MASSRUHÁ, S. M. F. S.; LEITE, M. A. de A.; MOURA, M. F. Os novos desafios e oportunidades das tecnologias da informação e da comunicação na agricultura (AgroTIC). In: MASSRUHÁ, S. M. F. S.; LEITE, M. A. de A.; LUCHIARI JUNIOR, A.; ROMANI, L. A. S.

(Ed.). Tecnologias da informação e comunicação e suas relações com a agricultura. Brasília, DF: Embrapa, 2014. Cap. 1. p. 23-38.

MATTOS, F. A. M.; CHAGAS, G. J. N. Desafios para a inclusão digital no Brasil. Perspectivas em ciência da informação, v.13, n.1, p.67-94, jan./abr. 2008.

Disponível em: https://www.scielo.br/pdf/pci/v13n1/v13n1a06.pdf. Acesso em 09 nov. 2011.

TOOGE, R. Apesar de expansão, mais de 70\% das propriedades rurais no Brasil não têm acesso à Internet. 2020. Disponível em:

https://g1.globo.com/economia/agronegocios/noticia/202 0/01/05/apesar-de-expansao-mais-de-70percent-das-prop riedades-rurais-no-brasil-nao-tem-acesso-a-Internet.ght ml. Acesso em 09 ago. 2020. 